\title{
UMA ANÁLISE AGROALIMENTAR: O CASO DOS AGRICULTORES QUILOMBOLAS DA RESERVA DE DESENVOLVIMENTO SUSTENTÁVEL QUILOMBOS BARRA DO TURVO-SP
}

\section{A AGRIFOOD ANALYSIS: THE CASE OF THE QUILOMBOLAS FARMERS SUSTAINABLE DEVELOPMENT RESERVE QUILOMBOS BARRA DO TURVO-SP}

\author{
Katia Maria Pacheco dos Santos \\ Universidade de Brasília - Brasília - DF - Brasil \\ Maria Elisa de Paula Eduardo Garavello \\ Universidade de São Paulo - São Paulo - SP - Brasil
}

\begin{abstract}
Resumo: O Vale do Ribeira concentra a maior área de Mata Atlântica do Estado de São Paulo sob o regime de Unidades de Conservação - UC e aproximadamente $21 \%$ do que existe no Brasil desse bioma. Além da rica diversidade ambiental, acrescenta-se a diversidade sociocultural, por abrigar comunidades tradicionais. Na região, há alterações quanto ao uso e ocupação da paisagem, com expansão do plantio de pupunha e pecuária. No território da Reserva de Desenvolvimento Sustentável Quilombos Barra do Turvo, criada em 2008, não há alterações na paisagem provocadas por expansão de monoculturas, ao contrário, nos últimos anos, a agricultura de base ecológica tem sido atividade notadamente revalorizada pelas famílias. O objetivo deste estudo foi analisar as práticas econômicas associadas à reprodução do sistema de produção alimentar local. A coleta de dados baseou-se na aplicação de entrevistas semiestruturadas, com levantamento da frequência de consumo alimentar e recordatório 24 horas. A função básica da agricultura é a produção de bens alimentares voltados ao consumo familiar e à comercialização pelo Programa de Aquisição de Alimentos - PAA. Além do contexto da manutenção da conservação dos recursos naturais e da segurança alimentar, as famílias mostram-se resistentes à adesão de hábitos de consumo alimentar contemporâneos.
\end{abstract}

Palavras-chave: Agricultura familiar. Segurança Alimentar. Desenvolvimento Sustentável. Quilombolas.

\footnotetext{
Abstract: The Ribeira Valley has the largest Atlantic Forest area of São Paulo State under the Protected Areas system and about $21 \%$ of what remains of this biome in Brazil. In addition to the rich environmental diversity, it adds up to sociocultural diversity, for harboring traditional communities. In the region, there are changes in the use and occupation of the landscape, expanding the planting of peach palm and livestock. Within the Sustainable Development Reserve Quilombos Barra do Turvo, created in 2008, there are no changes in the landscape caused by expansion of monocultures. Unlike in recent years, the ecological basis of agriculture activity has been particularly revalued by families. The aim of this study was to analyze the economic practices associated with the reproduction of the local food production system. Data collection was based on the application of semi-structured interviews, a survey of the frequency of food consumption and recall 24 hours. The basic function of agriculture is food production aimed at family consumption and marketing by the Food Acquisition Program. In the context of maintaining the conservation of natural resources and food security, families show themselves resistant adhesion contemporary food consumption habits.

Keywords: Family Agriculture. Food Security. Sustainable development. Quilombo.
} 


\section{Introdução}

Os colonos europeus estabelecidos na região do Vale do Ribeira durante o século XVII, mantinham a economia extrativista e agrícola utilizando-se de escravos negros, capturados em diversas regiões da África. Esses grupos realizaram intensamente trocas culturais e estabeleceram alianças entre si. Em caráter de resistência à escravidão, os que conseguiam fugir se refugiavam nas matas, formando os quilombos. Nas regiões onde se estabeleciam, desenvolviam modos particulares de vida, com estreita relação com a natureza, para sua sobrevivência. Segundo Carril (1995), as comunidades quilombolas se formaram a partir da libertação, fuga e/ou abandono dos escravos, após a decadência do ciclo econômico da mineração.

No Estado de São Paulo, especificamente na região do Vale do Ribeira, estudos antropológicos, afirmam a existência de comunidades quilombolas com tradição de ocupação nesta região há mais de três séculos. Esses grupos, mesmo com as mudanças culturais e a interconexão com o sistema capitalista, mantêm contato direto com a natureza, ora por questões de alimentação, moradia e/ou por ação de renda (STUCCHI, 1998). As comunidades quilombolas do Vale nunca viveram isoladas no contexto da produção agrícola regional, pelo contrário, tiveram intensa relação com essa atividade a partir de trocas estabelecidas (ITESP, 2000).

As comunidades quilombolas desenvolveram suas próprias estratégias de uso dos recursos ambientais disponíveis nas áreas do território do Vale do Ribeira, onde se estabeleceram. Mediante observação e experimentação, desenvolveram um extenso e minucioso conhecimento sobre os processos naturais que ordenam o meio ambiente local. Esse conhecimento pode ser profundamente codificado na bagagem tradicional e transmitido e refinado de geração a geração. Suas relações de produção estão baseadas no uso intensivo da mão de obra familiar e da tecnologia de baixo impacto (DIEGUES, 2000). Na maioria das terras quilombolas do Vale do Ribeira, observa-se mais de $80 \%$ com cobertura florestal, uma vez que as suas práticas de uso da terra são basicamente voltadas à manutenção alimentar e alguns cultivos voltados à comercialização (SANTOS e TATTO, 2008).

No período em que se estabeleceu a maioria das UC no Vale do Ribeira, a partir de 1960 até o início de 1990, em função das restrições de uso e ocupação do solo, as comunidades quilombolas foram forçadas a incorporarem outras formas de acesso aos recursos ambientais locais e novos meios para subsistência (BORN e TALOCCHI, 2002).

Atualmente, no território do Estado de São Paulo, existem 247 UCs, além das unidades municipais, e aproximadamente 200 unidades de conservação estaduais. Entretanto, para a implantação das unidades de conservação não só em território paulista, mas em todo o país, o Estado brasileiro seguiu o molde norteamericano, que não permitia a presença de habitantes nas áreas destinadas à proteção ambiental, mesmo que esses já habitassem e dependessem dela para reprodução de seu modo de vida. Diferentemente da realidade norte-americana, no Brasil, mesmo nas áreas de matas ao longo do litoral, já havia ocupação humana: caiçaras, campesinos de origem imigrante, campesinos migrantes de outras regiões do país, remanescentes de quilombos e grupos indígenas. Também em outras regiões do Brasil esse cenário era comum, gerando muitos debates com 
o objetivo de formular possibilidades para a construção de outras categorias de UC, em especial onde já havia presença humana, as chamadas "populações tradicionais". Foi então que no ano 2000, quando dos debates para criação da Lei Federal do Sistema de Nacional de Unidades de Conservação - SNUC, um dos pontos polêmicos tratava-se dos problemas gerados pela sobreposição de UCs em áreas tradicionalmente ocupadas por ribeirinhos, indígenas, caiçaras, quilombolas e outros grupos, como os seringueiros. Por fim, a aliança entre instituições governamentais, socioambientalistas, preservacionistas e população tradicional resultou na criação de novas categorias de áreas protegidas no SNUC, em que as populações tradicionais pudessem habitar e mesmo fazer uso sustentável dos recursos naturais, como são as Reservas de Desenvolvimento Sustentável - RDS.

Muitas comunidades quilombolas no Vale do Ribeira tiveram seus territórios destinados à proteção ambiental e, portanto, sofreram limitações ambientais, mesmo para a produção para o autoconsumo dos membros da família. Nos territórios onde foram estabelecidas unidades de conservação, a agricultura é considerada como uma prática impactante, prejudicial ao meio ambiente e, portanto, deve ser regrada.

Como resultado das leis de conservação que incidiram sobre esse território, as atividades de uso da terra para produção agroalimentar aos poucos foram se restringindo a pequenos espaços de cultivos. Isso intensificou a necessidade de obtenção de dinheiro, que lhes proporcionasse a compra dos alimentos que outrora eram produzidos na unidade doméstica e também de outros que não faziam parte da pauta alimentar, mas que em virtude dessas mudanças passaram a compor, ou mesmo substituir outros.

Analisar a questão alimentar, de acordo com a visão de Mintz (2001), no âmbito de comunidades rurais no mundo moderno, tornou-se mais complexo graças à crescente interconexão econômica que é mantida entre o campo e cidade. Brandão (2007), ao analisar trabalhos sobre hábitos alimentares em comunidades rurais tradicionais, identificou que estes são analisados a partir do espaço (um determinado "território") e da cultura, ao passo que aqueles realizados em áreas de assentamentos de reforma agrária são elaborados a partir de uma perspectiva do tempo e da história. $O$ autor afirma ser difícil encontrar um ponto de equilíbrio entre essas duas dimensões, mas que essas devem ser tratadas interconectadas, pois tanto a natureza quanto as sociedades humanas não existem nunca em separado.

A relevância de estudar os fatores que interferem na produção para autoconsumo decorre do fato de ser um importante meio para asseverar o que Candido (2001) denominou de mínimo vital, e cumprir outros papéis da agricultura familiar, como ser promotora de segurança alimentar, vetor de sociabilidade e estratégia de diversificação dos meios de vida, conferindo, assim, maior autonomia à população envolvida.

No Vale do Ribeira existem mais de 50 comunidades remanescentes de quilombos (SANTOS e TATTO, 2008). Ao longo dos anos, esses grupos observaram as várias tentativas de empreendimentos econômicos que ocorreram na região, como atividades extrativistas e agropecuárias, sendo as mais marcantes a suinocultura, cultivo de milho e feijão, extrativismo do palmito e, mais recentemente, a bovinocultura e a bubalinocultura. Em contraposição às atividades mencionadas, as comunidades quilombolas mantiveram suas práticas agrícolas 
mais voltadas à produção familiar de autoconsumo e algumas poucas culturas voltadas à comercialização. Como exemplo, o cultivo de banana na região do médio Vale do Ribeira, e o feijão e o milho para as comunidades quilombolas da Barra do Turvo, região do alto Vale do Ribeira.

O presente trabalho se constitui na abordagem do sistema agroalimentar na RDS Quilombos da Barra do Turvo no Vale do Ribeira/SP, a partir de uma análise sobre o modo de produção e consumo alimentar entre agricultores quilombolas habitantes dessa unidade de conservação de uso sustentável.

\section{Produção agroalimentar e segurança alimentar}

Ao longo da história, os agricultores domesticaram e continuam domesticando plantas silvestres e, por meio de um processo de seleção e melhoramento, adaptaram à agricultura e às suas necessidades. Diferentes sistemas agrícolas foram sendo desenvolvidos em várias partes do mundo (REIJNTJES et al., 1994), moldando o abastecimento e consumo de alimentos no mundo contemporâneo.

A agrobiodiversidade é fruto do manejo complexo e dinâmico dos cultivos agrícolas realizados pelos agricultores, e não pode ser reduzida a apenas um fenômeno natural; ela é também um fenômeno cultural (SANTILLI, 2009).

Os agricultores camponeses detêm saberes que possibilitam manipular uma base de recursos, o que thes garante autonomia (PLOEG, 2008), que se traduz no aprovisionamento alimentar pela produção familiar para autoconsumo. A organização da produção leva em conta os ciclos próprios da natureza, a partir dos quais se constroem as técnicas mais adequadas e os processos de trabalho. Em suas práticas produtivas, as comunidades expressam sua leitura do ambiente, desenvolvida num movimento de relações empíricas e cotidianas com o meio, na construção de seu modo de vida. A leitura que fazem do seu espaço ecológico remete aos usos que elas aí praticam, diretamente relacionados à reprodução da sua vida material e simbólica (FERREIRA, 2006).

Gazolla (2004) classifica o autoconsumo, também chamado de produção para subsistência, como uma característica própria da agricultura familiar. De acordo com Maluf (2009), a viabilização das atividades de produção agroalimentar continua sendo elemento essencial para a reprodução das famílias do meio rural, tanto como fonte direta de renda monetária e de alimentos para o autoconsumo quanto por fornecerem a base necessária para muitas das atividades não agrícolas. A produção para autoconsumo cumpre uma importante função ao manter internamente a unidade familiar e a satisfação de uma de suas necessidades vitais: a alimentação. Configura-se como uma estratégia que confere às unidades familiares maior controle sobre o processo produtivo e, por conseguinte, sobre a sua reprodução social (PLOEG, 2006).

No bojo do debate sobre segurança alimentar de povos e comunidades tradicionais, é preciso considerar como uma estratégia para tal a produção de autoconsumo, na qual a qualidade da alimentação pode ser gestada e gerenciada dentro da unidade familiar, em contraposição à subordinação imposta pela produção de alimentos em quantidade sem qualquer preocupação quanto à qualidade e à origem dos produtos. 
A manutenção da segurança alimentar em grupos humanos habitantes em UCs de uso sustentável está associada a uma mudança na forma de acesso aos recursos naturais e à implantação efetiva de uma política para reforma agrária. Entretanto, não há ou são incipientes as ações públicas voltadas para a melhoria da qualidade da vida humana. O SNUC não chegou a estabelecer uma categoria de unidade de conservação especialmente voltada para a proteção da agrobiodiversidade, cujo conceito reflete as dinâmicas e complexas relações que se estabelecem entre as sociedades humanas, as plantas cultivadas e os ambientes nos quais convivem, repercutindo sobre as políticas de conservação dos ecossistemas cultivados, de promoção à segurança alimentar e nutricional das populações, de inclusão social, bem como de desenvolvimento sustentável (SANTILLI, 2009). Todavia o Brasil, sendo signatário desde 2002 do Tratado Internacional sobre os Recursos Fitogenéticos para a Alimentação e a Agricultura, aprovado em Roma no ano de 2015, deve promover a conservação da agrobiodiversidade também em UCs.

A temática da segurança alimentar aparece mais explicitamente no cenário das políticas públicas brasileiras a partir de 1980. No bojo dos debates das políticas públicas a respeito da segurança alimentar, é observado que esta aponta além do aspecto da qualidade nutricional do alimento, o respeito aos hábitos culturais e aos modos de produção ecologicamente sustentáveis.

Segundo Maluf (2009), são três os pontos norteadores da segurança alimentar, sendo: a qualidade nutricional dos alimentos, inclusive a ausência de componentes químicos que possam lesar a saúde humana; os hábitos/cultura alimentar específicos de cada comunidade, de cada grupo social; e a sustentabilidade do sistema alimentar, ou seja, a contínua produção e presença de alimentos.

\section{Caminhos da pesquisa}

A pesquisa se baseou fundamentalmente em levantamentos de campo, partindo da investigação sobre os hábitos alimentares das famílias da RDS Quilombos da Barra do Turvo e as práticas agrícolas. Para tanto, foram selecionados indivíduos para realizar entrevistas seguindo o critério de uso e residência, ou seja, ser morador e exercer práticas agrícolas visando entender a diversidade dos sistemas agroalimentares e sua relação com os recursos naturais locais.

Utilizou-se questionário semiestruturado junto aos chefes de família. Nesse método, alguns tópicos são fixados e outros redefinidos conforme o andamento da entrevista e permite maior controle da situação pelo informante, ficando mais livre para o diálogo (VIERTLER, 1988).

Adotou-se ainda o método de frequência de consumo dos principais itens alimentares que constituem a dieta. O questionário de frequência de consumo, segundo Holanda e Barros Filho (2006), é um instrumento para apontar as preferências, bem como a frequência de ingestão de alimentos e bebidas. Utilizouse também a técnica do Recordatório 24 horas, que consiste na obtenção de informações verbais sobre a ingestão alimentar das 24 horas anteriores às consultas, com dados sobre os alimentos e bebidas consumidos. 
Também fez parte deste roteiro o levantamento da origem dos alimentos e/ou local de aquisição, bem como itens produzidos.

\section{A Reserva de Desenvolvimento Sustentável Quilombos e as Comunidades Quilombolas}

A RDS Quilombos de Barra do Turvo é uma das 14 UCs que compõem o Mosaico de Jacupiranga - MOJAC, criado em 2008 pela Lei 12.810/2008, após a recategorização do Parque Estadual do Jacupiranga (instituído em 1969 pelo Decreto Estadual $\left.n^{\circ} 145\right)$. Essa UC abrange quatro bairros de origem quilombola: Cedro, Terra Seca, Ribeirão Grande e Pedra Preta-Paraíso e está localizada no Município de Barra do Turvo/SP. A área geográfica é de 5.826,46 hectares, localizada a $320 \mathrm{~km}$ de distância da cidade de São Paulo e a $150 \mathrm{Km}$ de Curitiba. O acesso a essa Unidade de Conservação é por meio da Rodovia BR-116 e da SP552.

Segundo o Relatório Técnico-Científico sobre os quilombos remanescentes das comunidades de quilombo Ribeirão Grande e Terra Seca, Município de Barra do Turvo, o estabelecimento de ex-escravos onde hoje é a RDS se deu por volta de 1817 (ITESP, 2006).

Atualmente, estima-se que sejam aproximadamente 136 famílias quilombolas residentes no território da RDS. Essas famílias pertencem a uma rede comum e extensiva de relações entrelaçadas de parentesco. A maior parte das casas está situada ao longo das margens do Rio Turvo e Ribeirão Grande. São casas em grande parte de madeira e algumas de alvenaria. A água que abastece as casas é captada de minas d'água e transportada por meio de canos até as casas. Não há tratamento de água e esgoto, e muitas casas não tem energia elétrica.

No total foram entrevistados 28 famílias, na maioria mulheres e na faixa etária média de 51 anos. O número de residentes dos núcleos domésticos entrevistados, em média, é de quatro membros, composto pelo casal e dois filhos e/ou netos em idade escolar. Somente quatro entrevistados afirmaram morar sozinhos, três eram senhoras viúvas e um senhor viúvo. Em geral, todos os entrevistados informaram que a maioria dos filhos e netos têm residência em Curitiba, porque estão trabalhando (empregados em lojas no comércio ou na construção civil) e, aos fins de semana ou datas festivas, retornam para visitar os familiares.

No território da RDS não tem escola de ensino fundamental e médio. Os alunos se descolam de ônibus escolar até os bairros Rio Vermelho e Rio Indaiatuba, ainda no Município de Barra do Turvo para cursar a escola. Não há Posto de Saúde e, mesmo nos casos mais simples, os moradores necessitam ir até a sede do Município de Barra do Turvo.

Como pode ser observado no Gráfico 1, dos 28 entrevistados, 20 indicaram ter algum membro da família residente recebendo o benefício da aposentadoria por idade ou como agricultor familiar. Como principal fonte de renda obtida por meio do uso da terra está à venda a Companhia Nacional de Abastecimento CONAB por meio do Programa de Aquisição de Alimentos - PAA e entrega a uma Cooperativa de agricultores familiar local que comercializa também por meio do PAA e em feiras em Curitiba. 
Com relação a fontes de renda, 34\% dos entrevistados afirmaram ter renda mensal de 1 salário mínimo, 33\% informaram ter renda entre 1 e 2 salários mínimos e 33\% afirmaram ter renda mensal entre 2 a 3 salários mínimos.

A carência financeira é apontada como um dos problemas enfrentados e que ocasiona grande parte da população mais jovem a abandonar o trabalho rural na comunidade e migrar rumo aos centros urbanos, principalmente Curitiba, à procura de ocupação temporária ou algum emprego assalariado. Essa falta de meios de geração de renda e a dificuldade de acesso ao ensino formal de segundo grau leva, até os dias de hoje, jovens e adultos a buscar oportunidades fora e deixar a RDS. Esse fato, resulta numa crescente desvalorização e perda dos padrões alimentares tradicionais, além de outros problemas como a diminuição de mão de obra familiar nas atividades agrícolas.

Gráfico 1. Fontes de renda indicadas pelos entrevistados

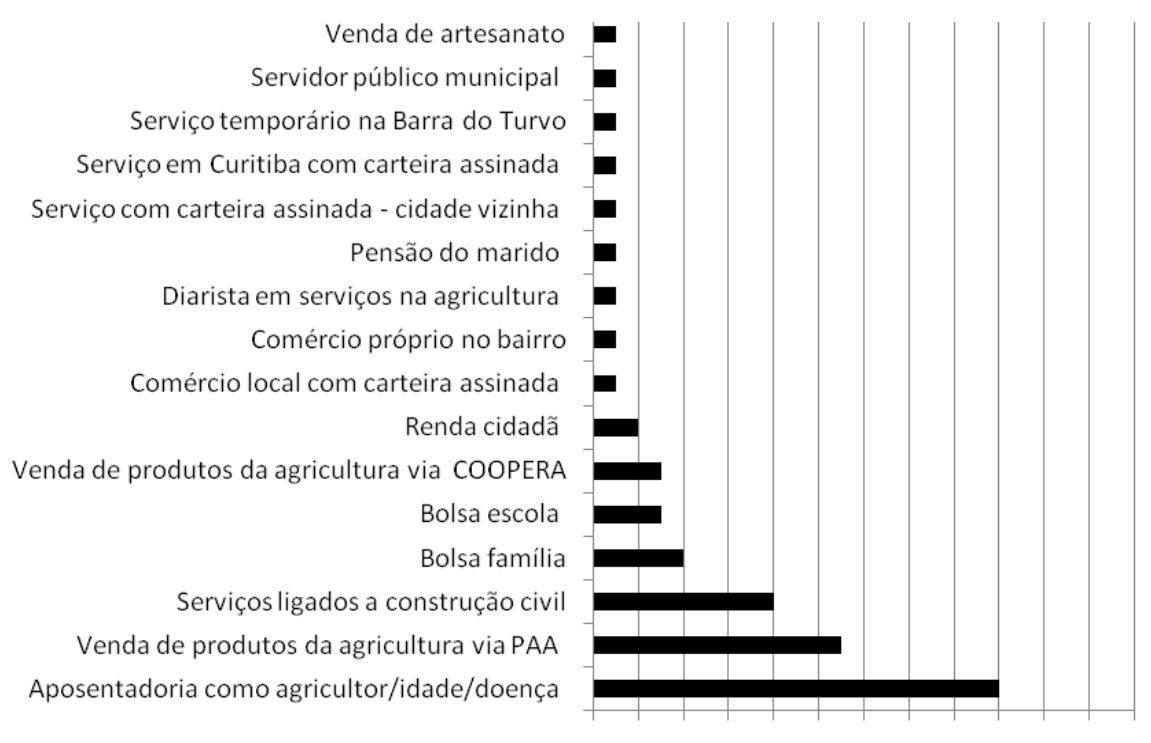

Fonte: elaboração própria.

\section{1 Produção agroalimentar}

De acordo com o Plano de Utilização da RDS Quilombos de Barra do Turvo, documento elaborado em 2010, seguindo o disposto na Lei Federal no 9.985/2000 do SNUC, estima-se que, pelo menos, 35\% da área da RDS se dá com cobertura florestal em estágio avançado de conservação. Cerca de $40 \%$ da área total da RDS apresenta algum tipo de uso da terra (atividades de criação de gado e/ou monocultivo de pupunha, mandioca e cana), $6 \%$ com uso baseado em sistema agroflorestal e outros $6 \%$ estão sendo utilizados para o estabelecimento de roças tradicionais, também conhecida como roça de coivara.

De acordo com o levantamento dos pedidos de autorizações submetidos ao Conselho Deliberativo da RDS, desde sua criação no ano de 2009, observa-se que as mesmas tiveram aumento de quase 75\% nos anos de 2011 e 2012, se 
comparado com o ano de 2010. Pode-se justificar esse acréscimo em virtude da recategorização da UC que sobrepunha às comunidades quilombolas, que ao deixar de ser um Parque, portanto, uma UC onde a prática agrícola das comunidades era considerada um dano ao meio ambiente. Quando passou a ser uma unidade de conservação de uso sustentável, sendo classificada como RDS, portanto, um dos seus objetivos é garantir às comunidades tradicionais as condições e os meios necessários para a reprodução e a melhoria dos modos e da qualidade de vida e uso dos recursos naturais. Portanto, as comunidades praticam hoje a agricultura tradicional sem o medo de cair sobre eles multas ou mesmo serem considerados inimigos do meio ambiente.

As roças ocupam pequenas áreas no espaço geográfico que cada família considera ser seu "sítio" e não ultrapassam o tamanho médio de 1,5 hectare. Após a derrubada da cobertura vegetal, é realizado aceiro de, pelo menos, três metros ao redor de toda a área e, somente depois, utiliza-se o fogo, o que evita o risco de incêndio em outra área que não seja a que está sendo preparada para ser cultivada.

Constatou-se que as roças quilombolas denotam o saber-fazer (o modo de manejo dos recursos naturais) associado ao modo de manutenção das relações sociais no trabalho no âmbito familiar. Esse aspecto aponta que o enfoque dado pela multifuncionalidade contribui para ressaltar as várias funções da agricultura e, dentre elas, a manutenção do tecido social e cultural das famílias rurais (CARNEIRO e MALUF, 2004).

As áreas de interesse para o estabelecimento das roças tradicionais são determinadas pela maturidade da vegetação existente por influenciar diretamente na fertilidade do solo. Por exemplo, uma área de "capoeirão" é sempre considerada como excelente para o estabelecimento de uma roça, por se tratar de uma área que há muitos anos, pelo menos mais de 12 anos, não foi cultivada. A área com vegetação florestal classificada como de capoeira (em média com sete anos sem cultivo) pode não apresentar as condições ideais para se garantir uma boa produção, mas, ainda assim, é uma área de interesse para se estabelecer uma nova roça tradicional. Já uma capoeirinha é uma área com vegetação mais jovem e como pouco acúmulo de matéria orgânica sobre o solo, portanto, uma área ruim para o estabelecimento de uma roça tradicional. Normalmente, inicia-se o cultivo com o plantio de semente de feijão e de milho, depois da colheita, na mesma área, planta-se a mandioca, a batata-doce e a abóbora. Podem, nessa mesma, área serem plantadas mudas de cana-de-açúcar, abacaxi e mamão. Quando é uma roça de arroz, apenas planta essa semente e depois da colheita é que se introduz outros cultivos na área, como a mandioca. Explicitamente, observou-se que as áreas se caracterizam por policultivos de interesse alimentar para a unidade doméstica.

De modo geral, as áreas onde são estabelecidas as roças são distantes da casa do agricultor e em área que os animais, como galinhas e gado não têm acesso. Já os cultivos de ciclo mais curto, como as hortaliças, são cultivadas em espaços nas proximidades das casas. Como pode ser observado na Tabela 1, nos pomares há 25 tipos de frutíferas, sendo 4 variedades diferentes de banana. Há também 37 tipos de verduras e legumes e 5 tipos de temperos. 
Quadro 1. Tipos de frutas, verduras, legumes e temperos que são cultivados nas comunidades quilombolas da RDS

\begin{tabular}{|c|l|}
\hline $\begin{array}{c}\text { Verduras e } \\
\text { Legumes }\end{array}$ & $\begin{array}{l}\text { Abobrinha, Milho, Alface, Quiabo, Almeirão, Nabo, Agrião, Maxixe, Acelga, } \\
\text { Pepino, Brócolis, Tomate, Batata-doce, Mandioca, Abóbora, Rabanete, } \\
\text { Beterraba, Rúcula, Berinjela, Mostarda, Couve, Vagem, Chuchu, Repolho, Cará, } \\
\text { Couve-flor, Chicória, Cenoura, Espinafre, Escarola, Feijão pardinho, Jiló, } \\
\text { Gengibre, Inhame, Mandioquinha }\end{array}$ \\
\hline Frutas & $\begin{array}{l}\text { Abacaxi, Abacate, Banana nanica, Banana da terra, Banana ouro, Banana maça, } \\
\text { Banana prata, Ameixa amarela, Acerola, Caqui, Carambola, Fruta do conde, } \\
\text { Figo, Jabuticaba, Jaca, Laranja, Goiaba, Graviola, Maracujá doce, Maracujá } \\
\text { azedo, Limão, Mamão, Pêssego, Tangerina, Ponkan }\end{array}$ \\
\hline Temperos & Cheiro verde, Cebolinha, Pimentão, Pimenta, Salsa \\
\hline
\end{tabular}

Fonte: elaboração própria.

Observa-se que parte da fonte alimentar das comunidades quilombolas da RDS é proveniente de suas roças de milho, mandioca, feijão, cana e banana. No entanto, a manutenção dessa pratica é mantida mais pelos pais, isso porque os filhos não têm interesse na agricultura, limitando, assim, a capacidade de mão de obra do grupo familiar para o exercício da atividade.

Dos entrevistados, 23 afirmaram ter roça, e somente 5 disseram não ter porque não têm mão de obra para ajudar ou mesmo pela idade avançada não consegue mais trabalhar na lavoura. Observou-se que $40 \%$ dos entrevistados afirmaram que a mão de obra para a atividade de produção alimentar é a do casal, $22 \%$ disseram que a mão de obra é das mulheres, $4 \%$ afirmaram ser do sexo masculino a mão de obra. Ainda, 17\% afirmaram que a mão de obra é do casal e, esporadicamente, há contribuição dos filhos, $13 \%$ já indicaram que ser a mão de obra do chefe da família (o pai) com a ajuda dos filhos e somente $4 \%$ disseram que esporadicamente há mão de obra de fora do núcleo doméstico, ou seja, um contratado para ajudar o casal a realizar as atividades agrícolas.

A produção para autoconsumo engloba pequenas criações de galinhas, hortas, pomares e pequenas roças. Entre os itens produzidos no pomar estão: abacaxi, abacate, banana nanica, banana da terra, ameixa amarela e laranja. Nas roças: feijão (pardinho e preto), cana, mandioca, abóbora e milho. Nas hortas: alface, couve, beterraba, pepino, chicória, abobrinha, almeirão, agrião, brócolis e temperos.

As sementes destinadas para o plantio nas áreas de roça são adquiridas comumente em lojas agropecuárias na cidade de Barra do Turvo, e algumas vezes fornecidas pelo Instituto de Terras do Estado de São Paulo - ITESP. Somente três entrevistados afirmaram guardar de um ano para o ano seguinte sementes de arroz, milho e feijão. Nas roças não se utiliza nenhum tipo de insumo químico. No caso dos entrevistados que têm horta e gado dizem utilizar o esterco decomposto.

Alguns agricultores cultivam pequenas áreas de pupunha. Somente 9 dos 28 entrevistados afirmaram ter criação de gado, 18 entrevistados indicaram criar 
galinha para obtenção de ovos e carne, somente 3 indicaram ter porcos e apenas um com meliponicultura.

\subsection{A Origem dos Alimentos}

A compra de alimentos é realizada predominantemente em supermercado na cidade da Barra do Turvo. Na ocasião da compra, o indivíduo paga a dívida da compra do mês anterior e uma nova é gerada. Dessa forma, o aposentado ou trabalhador assalariado se mantém fiel ao comerciante, pois, todo mês na ocasião do pagamento é também o dia de fazer a compra do mês.

Entre as famílias entrevistadas, $60 \%$ dos alimentos são obtidos por meio da compra e cerca de $40 \%$ são produzidos nas roças e pomares das casas. Esses dados reforçam a ideia da recategorização da UC e sua importância para a produção de itens alimentares das famílias, a partir do momento em que houve a permissão da abertura de áreas para o cultivo.

Esse resultado evidencia a importância da produção para abastecimento das famílias. Pelo contrário, pesquisas têm demonstrado a incapacidade de abastecimento das necessidades da família por meio da produção local. De acordo com Silva e Costabeber (2013), em pesquisa com assentados, verificaram que a produção é orientada para a adoção de tecnologias em sintonia com o desenvolvimento capitalista, com rompimento da produção para autoconsumo. Aliado a esse fator, a maior parte dos jovens do assentamento pesquisado está optando por sair do meio rural, buscando trabalho no meio urbano, fato esse também verificado em nossa pesquisa, e que compromete a mão de obra disponível para a produção local.

Pôde-se observar que entre os agricultores quilombolas alguns plantam para seu autoconsumo e criam alguns animais, enquanto outros, principalmente os casais aposentados, adquirem a grande maioria dos bens alimentícios em mercados. Também observou-se que alguns entrevistados fazem a compra picada, que é aquela realizada para obter um ou outro tipo de alimento que não foi suficiente para abastecer o mês inteiro. Comumente os alimentos adquiridos nessa compra são as carnes, verduras e leite. Essa compra é realizada no comércio local. Somente na comunidade Cedro é que não há nenhum mercadinho local, mas nas outras três que compõe a RDS, há pelo menos três pontos de venda de alimentos e outros itens, o chamado mercadinho de bairro. De acordo com $72 \%$ dos entrevistados, o custo mensal com compra de alimentos está em torno de $\mathrm{R} \$$ 300,00 a $R \$ 400,00$ e para os demais $28 \%$, entre $R \$ 450,00$ a $R \$ 600,00 /$ mês. De acordo com Grisa et al. (2010) entre agricultores no Rio Grande do Sul, o custo com compra de alimentos chegou a R\$360,00/mês, e cerca de 30\% dos alimentos consumidos pelas famílias eram produzidos localmente, permitindo à família o controle sobre parte de sua alimentação e sobre sua autonomia.

\subsection{A Pauta Alimentar}

As refeições dividem-se em: café da manhã, entre $6 \mathrm{~h} 30$ e 7h; almoço ao meio-dia; lanche da tarde, entre 15 e 16h30; e, por fim, o jantar entre 18 e 20h.

O café puro com açúcar é o alimento ingerido por $57 \%$ dos entrevistados no café da manhã. Somente $53,5 \%$ dos entrevistados disseram ter ingerido algo 
junto com o café, como banana, bolachas, bolo, mandioca, paçoca, pão, farofa de ovo ou virado de banana, conforme observado no gráfico 2 .

\section{Gráfico 2. Alimentos consumidos no café da manhã}

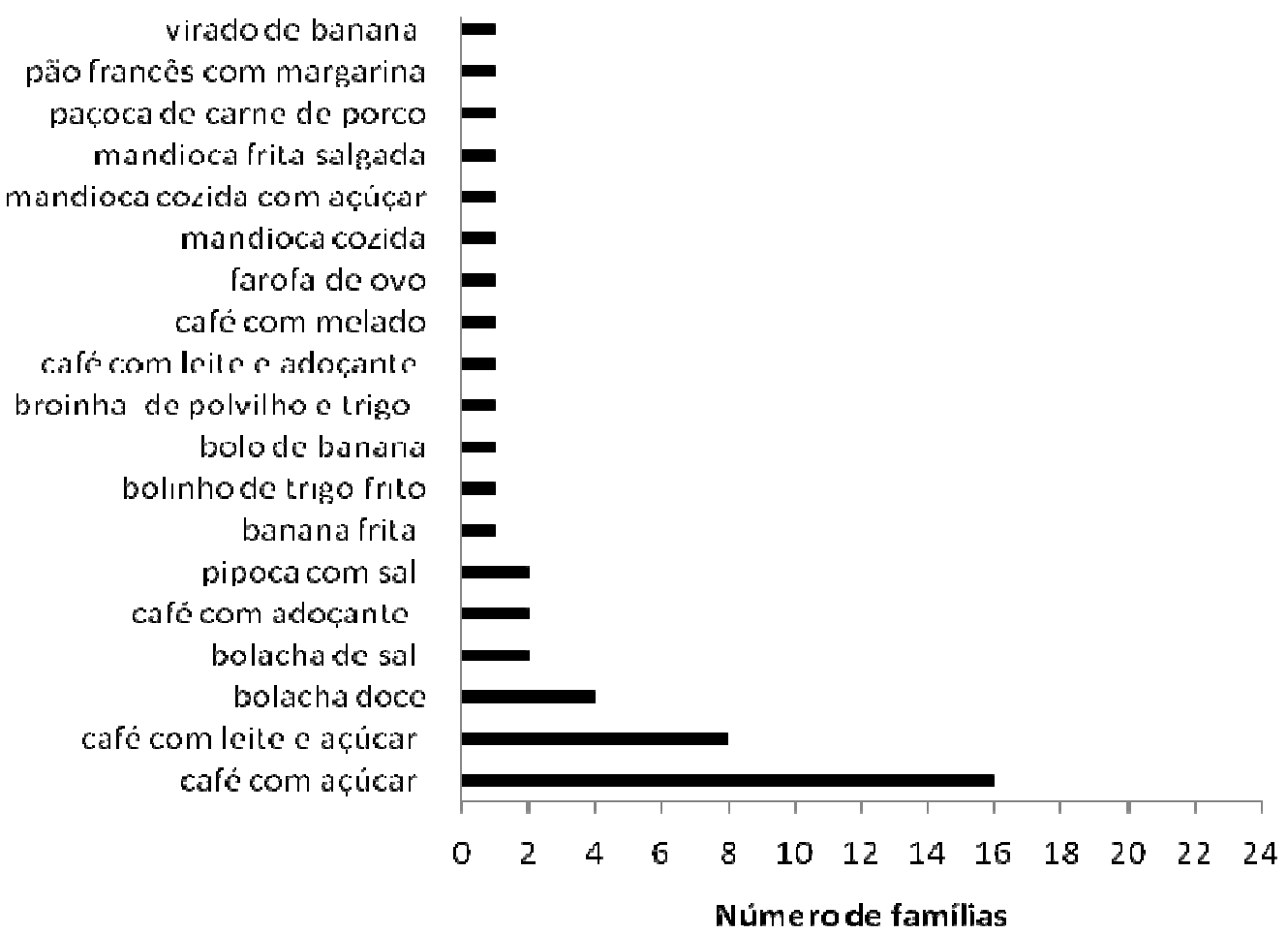

Fonte: elaboração própria.

O recordatório 24 horas e a frequência de consumo apontaram que o almoço, basicamente, é composto por feijão, arroz e farinha de milho (gráficos 3 e 4) e o consumo de proteína de origem animal, como frango, gado e suíno são alimentos consumidos por $65,3 \%$ das famílias, e ovos e peixe estão presentes na dieta de menos de $1 \%$ dos entrevistados, como verificado nos gráficos 3,5 e 8 . Em estudo realizado com comunidades quilombolas no Paraná, o frango foi citado como uma das carnes mais consumidas (CAMBUY, 2006). Esse fato também foi observado em comunidades no Vale do Ribeira, incluindo também o consumo frequente de ovos (NAVAS et al., 2015). Figueiredo et al. (2011) verificaram que os principais alimentos consumidos em uma comunidade quilombola no Rio Grande do Sul eram arroz, feijão, carne e massas.

Para $61 \%$ dos entrevistados o consumo de legumes e verduras faz-se presente na hora do almoço (gráfico 6). Entre as hortaliças destaca-se a couve e a alface. No café da tarde algumas comidas consideradas como tradicionais foram consumidas por $28,5 \%$ dos entrevistados, como por exemplo o cuscuz de fubá com amendoim e farinha de mandioca (gráfico 7). 


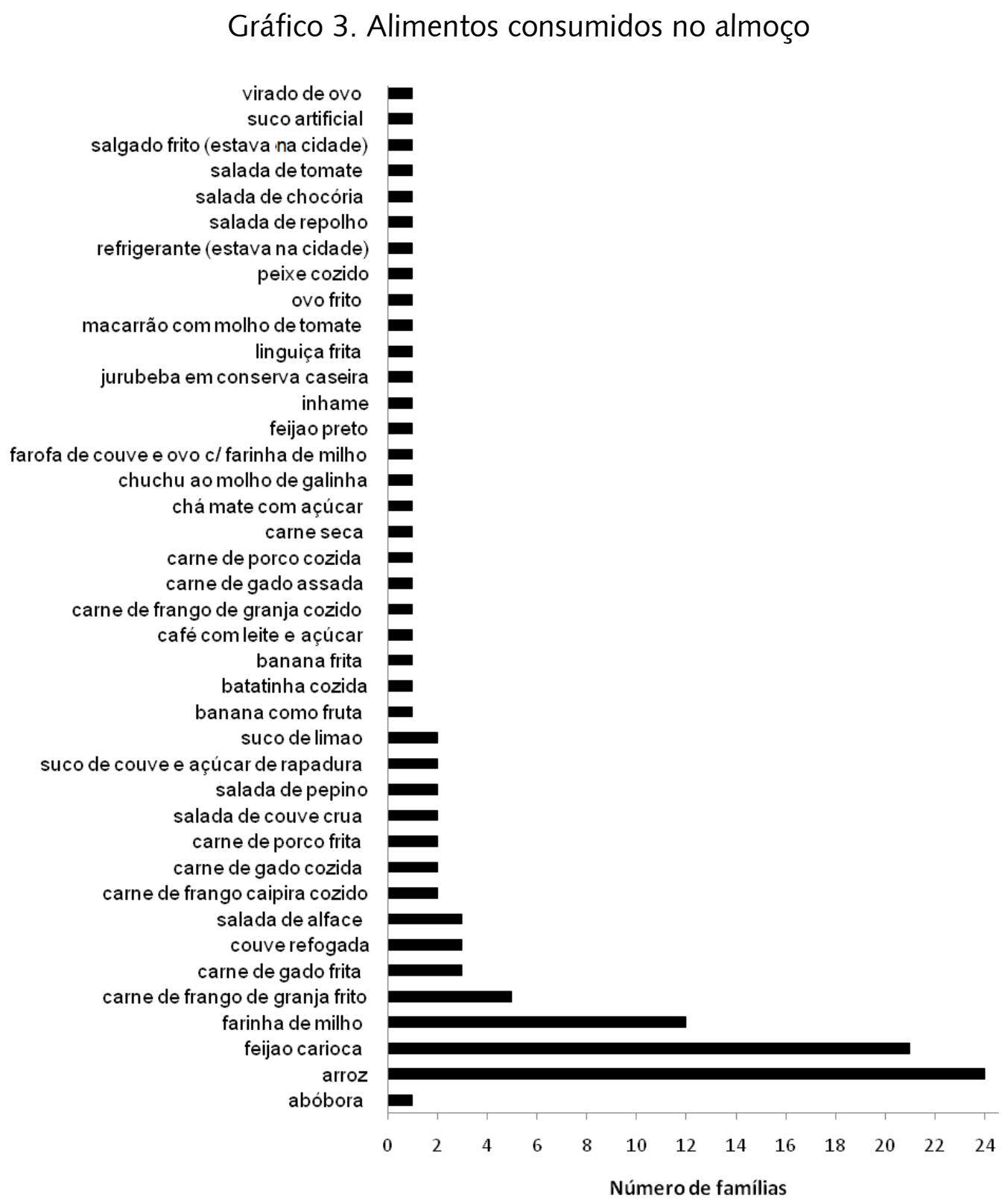

Fonte: elaboração própria.

No jantar, observou-se que os alimentos consumidos no almoço são novamente repetidos. Isso porque o almoço já é preparado em quantidade para que sobre para o jantar, podendo haver algum incremento de sopa de mandioca ou feijão ou mesmo de macarrão (gráfico 8). Em geral não há consumo de doces ou frutas após as refeições.

Ainda sobre a farinha de milho, ela é a preferida pelas comunidades quilombolas da RDS, diferentemente de outras comunidades quilombolas do Vale do Ribeira que tem a tradição do consumo da farinha de mandioca. Uma justificativa para tal preferência é a influência dos hábitos alimentares dos campesinos sulistas, onde o milho é uma cultura típica e se faz bastante presente na dieta alimentar. Infelizmente, hoje, não há nenhum monjolo em funcionamento em nenhuma das comunidades quilombolas que compõe a RDS. Os entrevistados 
informaram que não há produção de farinha de milho devido ao tamanho das roças que hoje são cultivadas. As restrições quanto ao uso da terra, que até 2008 era Parque, não permitiam fazer roças grandes dessa cultura, o que é necessário para a produção da farinha. Outro motivo é que somente algumas pessoas mais velhas têm o conhecimento necessário para tal produção e alegam não ter condições para assumir a mobilização de mutirão para o plantio de uma roça de milho que seja suficiente para gerar matéria-prima. Hoje, a farinha de milho é adquirida na compra do mês, pois é considerada companheira do feijão e do arroz. Ainda é componente da alimentação do dia a dia, como por exemplo, o virado de feijão, o virado de banana, a farofa de couve, a farofa de ovo, a paçoca de amendoim e a paçoca de carne de porco.

Conforme apresentado no gráfico 4, o arroz, o feijão e a farinha de milho são alimentos que compõem a dieta alimentar de praticamente todos os entrevistados. O feijão é o alimento mais produzido entre os agricultores quilombolas. Já o arroz deixou de ser cultivado pela maioria.

As famílias fazem consumo de frutas, verduras e legumes em geral uma vez na semana, conforme se observa no gráfico 6 . Destaca-se as verduras e legumes que são mais consumidos: o tomate, cenoura e repolho, nessa ordem de preferência. Souza e Soares (2011) verificaram, em estudo com comunidade quilombola, que a agricultura apresentava redução, com menor oferta de alimentos e dependência da compra de produtos básicos, como feijão e arroz, e baixo consumo de frutos e verduras. Figueiredo et al. (2011) também observaram baixo consumo de frutas e verduras em comunidade quilombola no Sul do Brasil. Navas et al. (2015) também verificaram baixo consumo de frutas e hortaliças e produção insuficiente para abastecimento da família, com maior importância da compra de produtos básicos na alimentação no Vale do Ribeira.

O café, seguido do leite (gráfico 9) aparecem como bebidas consumidas frequentemente. Nota-se que o consumo de óleo, sal e açúcar está presente na dieta dos quilombolas da RDS (gráfico 10), onde se constata ingestão mais de três vezes na semana, ou seja, frequente e baixo consumo dos demais itens industrializados, diferentemente de outras pesquisas, que evidenciam o aumento no consumo desses produtos entre comunidades tradicionais (NAVAS et al., 2015; SOUZA e SOARES, 2011; SILVA e BEGOSSI, 2007; PIPERATA, 2007; CAMBUY, 2006; CGPAN, 2005). Segundo Silva e Costabeber (2013), entre assentados do Rio Grande do Sul, foi observada a adoção de práticas alimentares muito semelhantes às do meio urbano, com elevado consumo de alimentos industrializados, principalmente pela proximidade com o meio urbano e comodidade de comprar ao invés de produzir, além dos preços baixos dos alimentos industrializados.

Essa diferença na alimentação pode estar relacionada à mudança na categoria da UC, permitindo a produção de alimentos nas roças, o que tem proporcionado a comercialização por meio do PAA e contribuído para produção para autoconsumo. O PAA apresenta-se como uma oportunidade de incentivo à prática da agricultura de pequena produção pelos agricultores quilombolas, sendo um potencializador da produção agroalimentar e possibilidade de garantia de comercialização, ao mesmo tempo tem fortalecido a prática da pequena produção e possibilitado a produção e o consumo de alimentos saudáveis, isentos de agrotóxicos. 
Gráfico 4. Frequência de consumo de grãos, amidos e carboidratos na alimentação das famílias na RDS

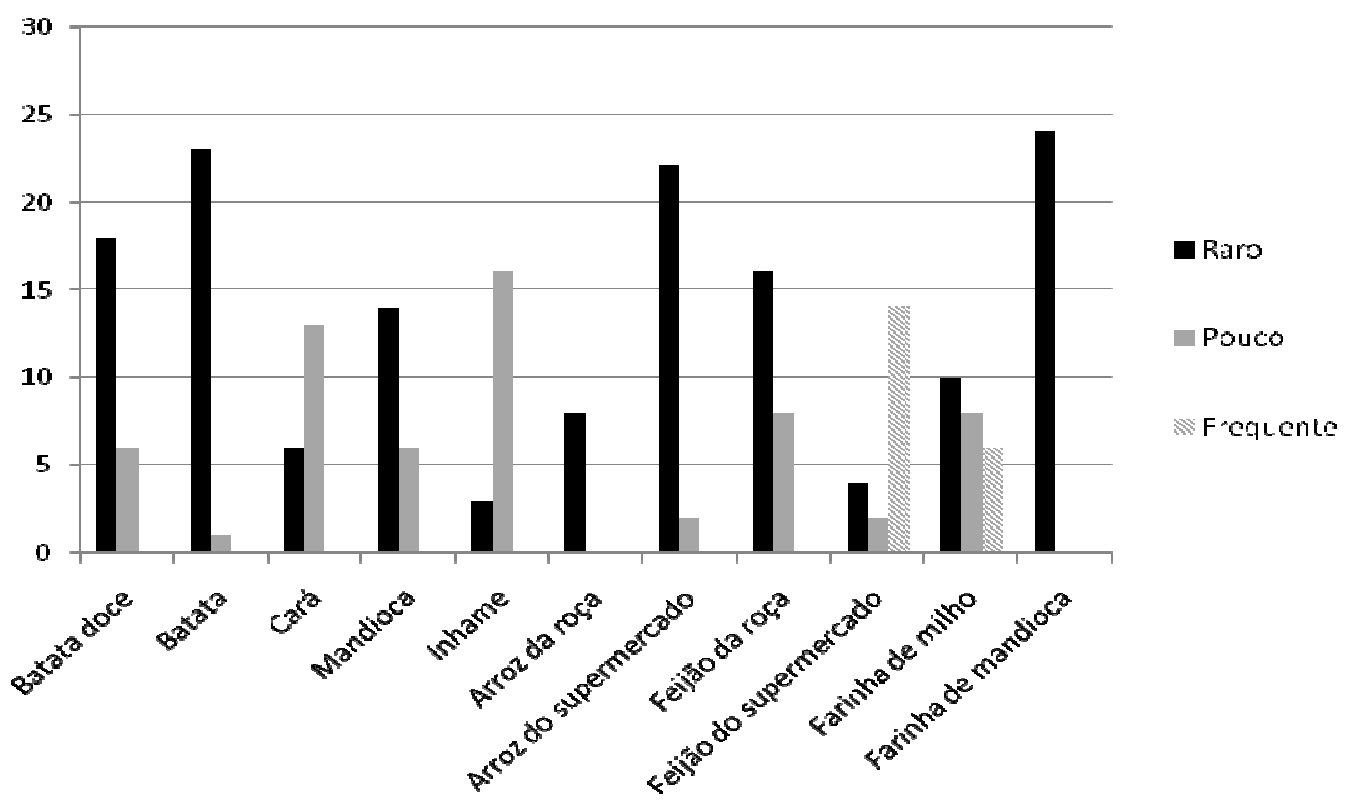

Fonte: elaboração própria.

Gráfico 5. Frequência de consumo das fontes de proteína de origem animal na alimentação das famílias na RDS.

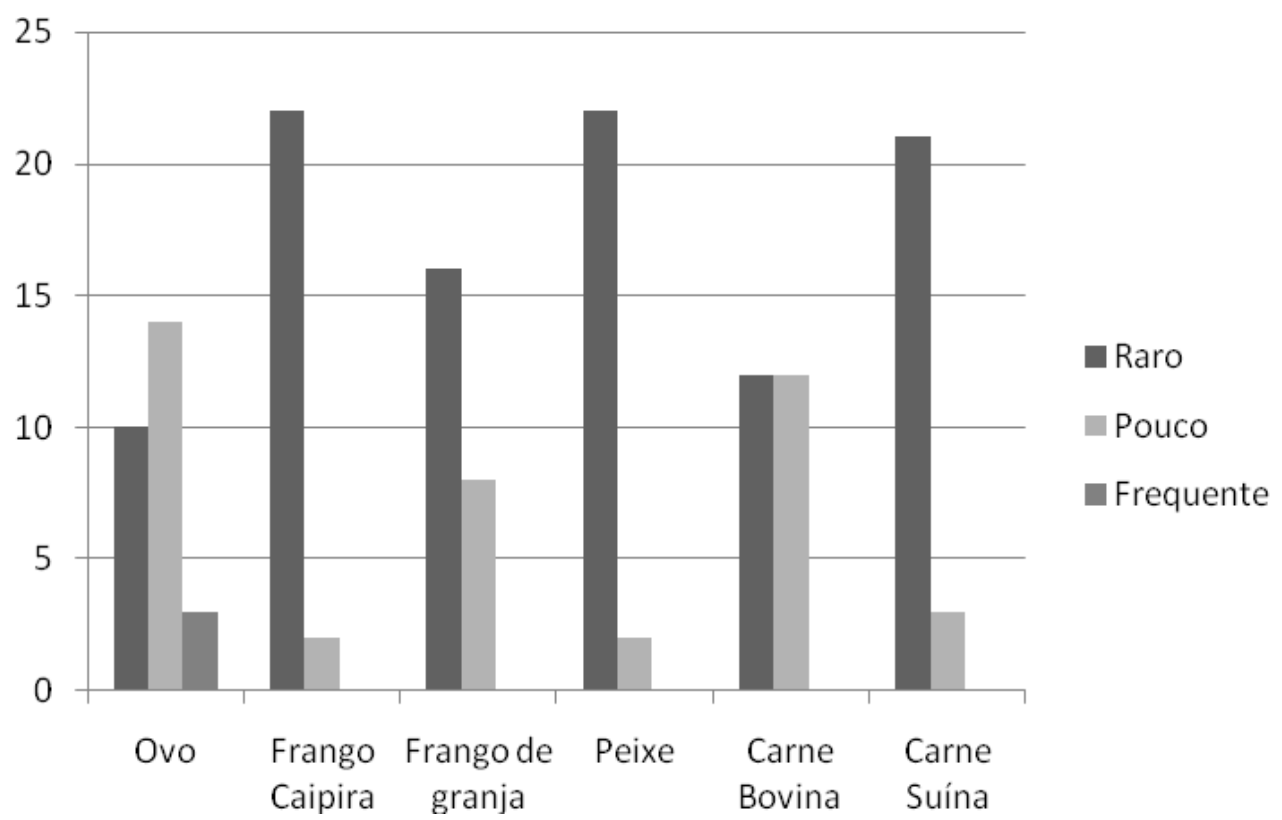

Fonte: elaboração própria. 
Gráfico 6. Frequência de consumo de frutas, legumes e verduras na alimentação das famílias na RDS

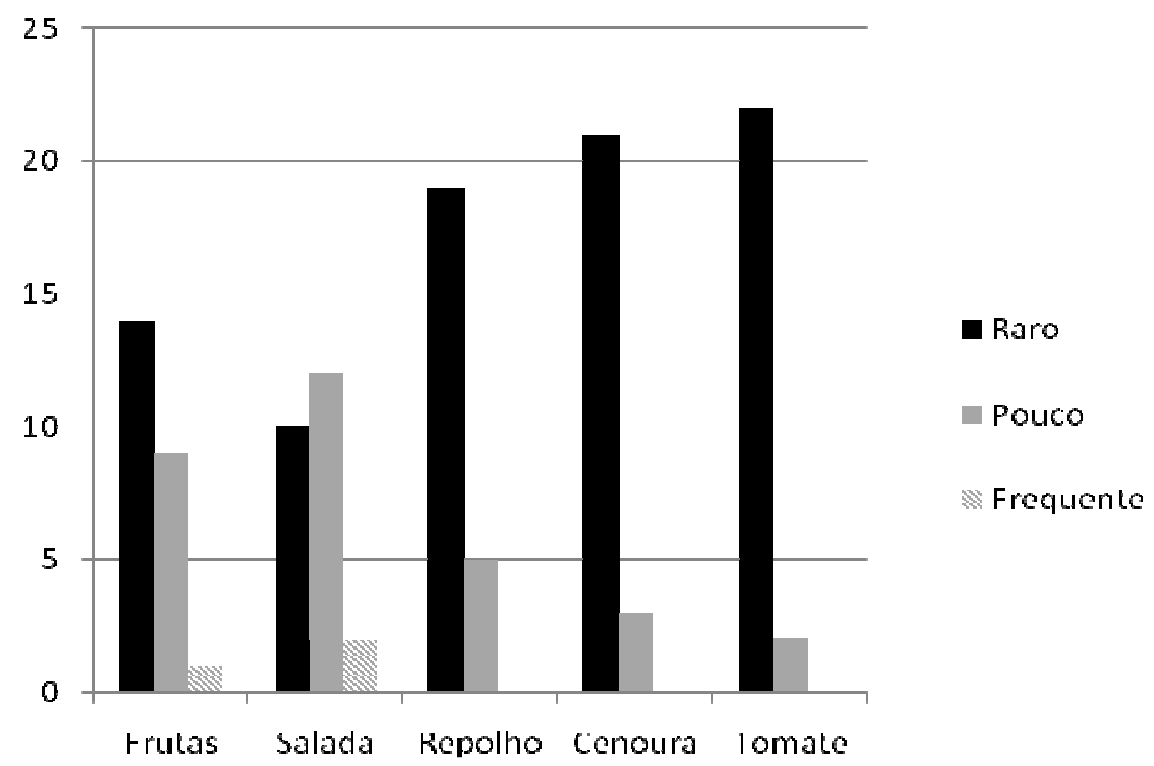

Fonte: elaboração própria.

Gráfico 7. Alimentos consumidos no café da tarde

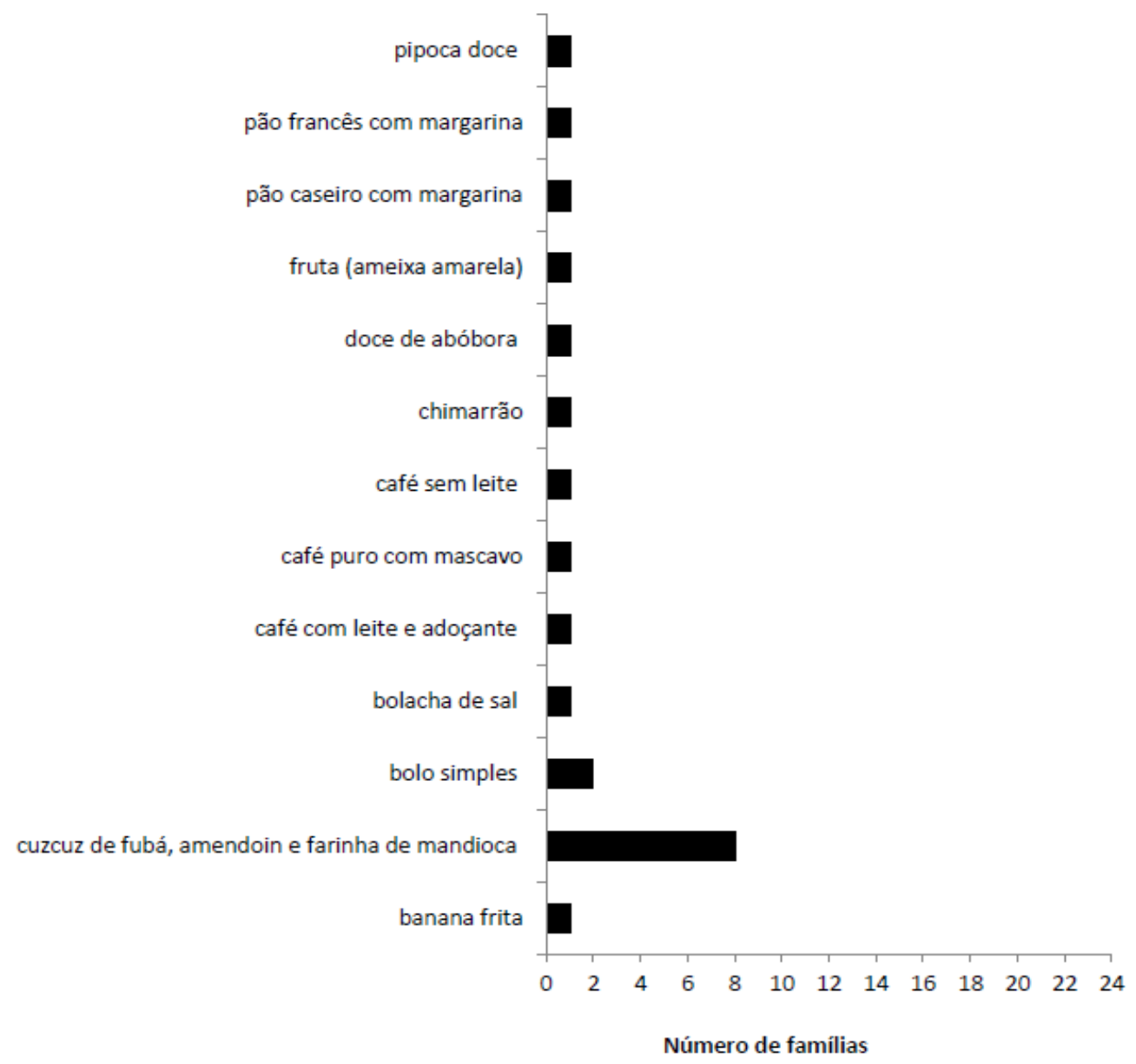

Fonte: elaboração própria. 


\section{Gráfico 8. Alimentos consumidos no jantar}

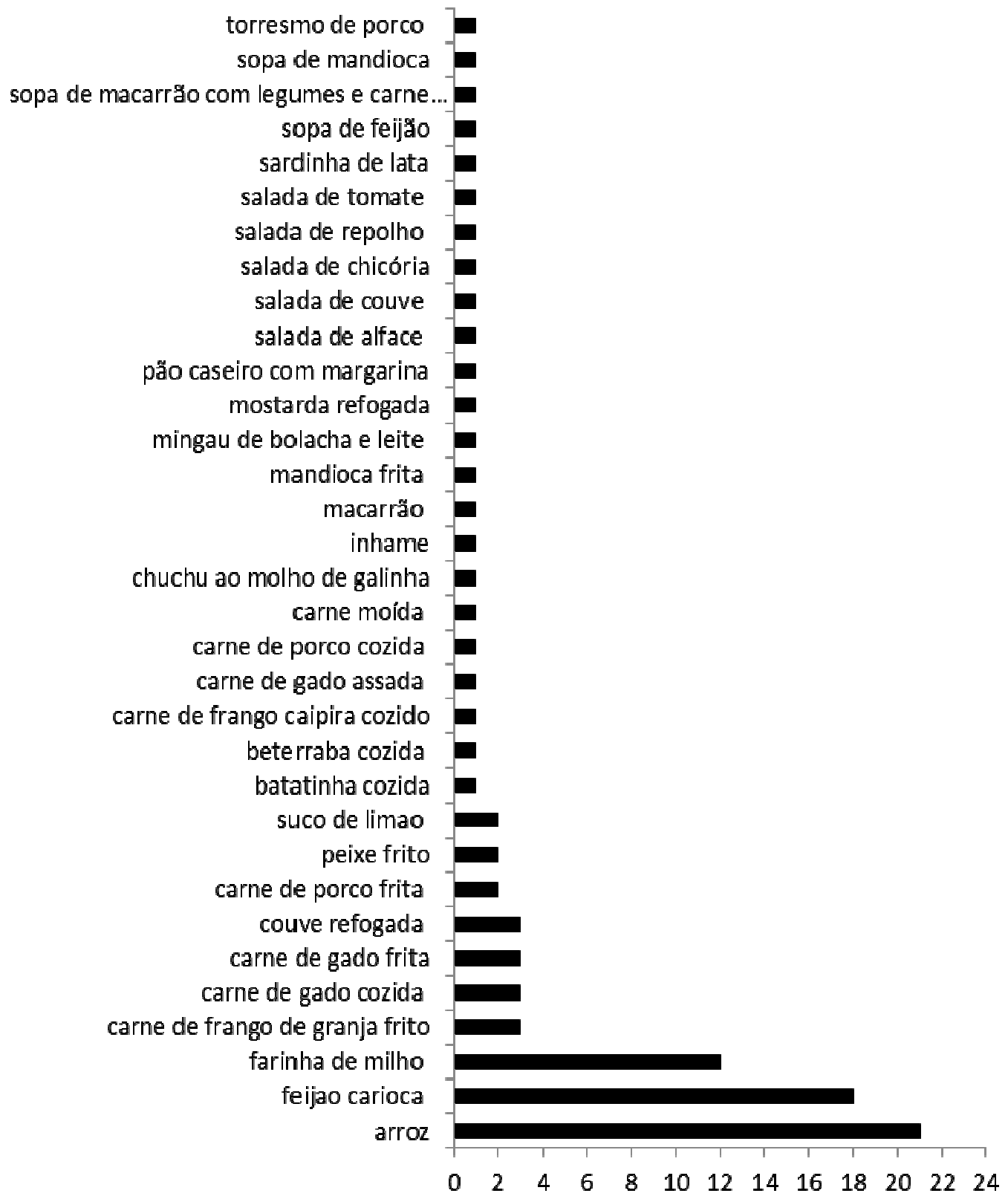

Número de famílias

Fonte: elaboração própria. 
Gráfico 9. Frequência de ingestão de bebidas pelas famílias na RDS

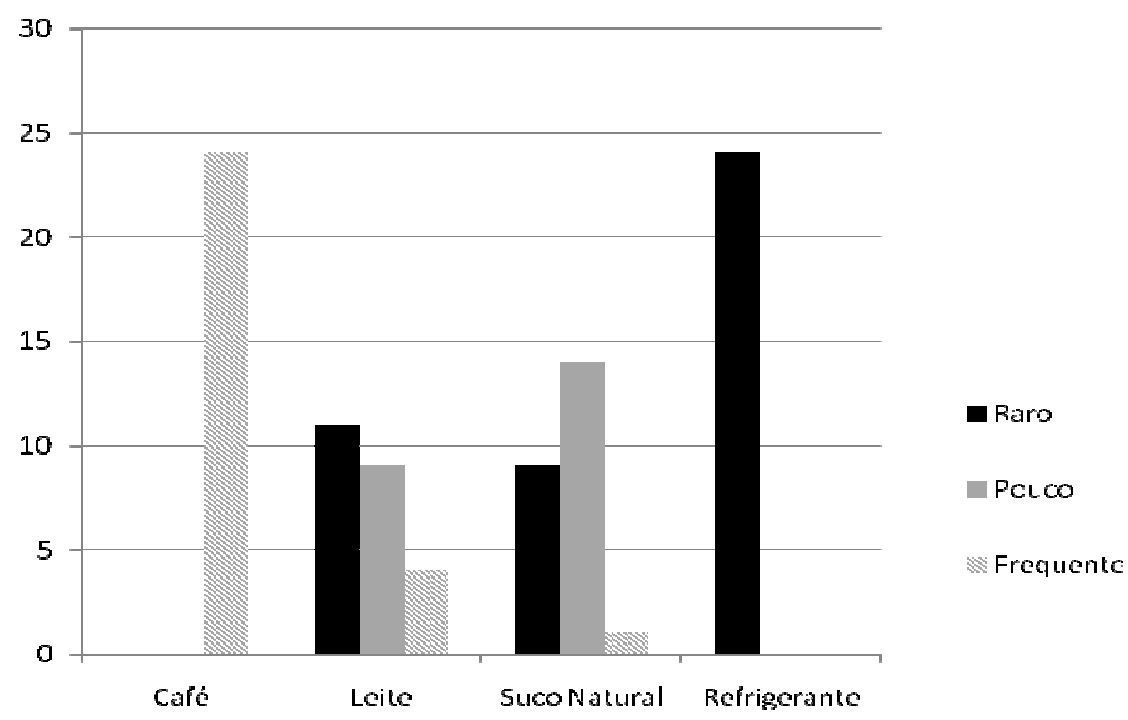

Fonte: elaboração própria.

Gráfico 10. Frequência de consumo de alimentos industrializados pelas famílias na RDS

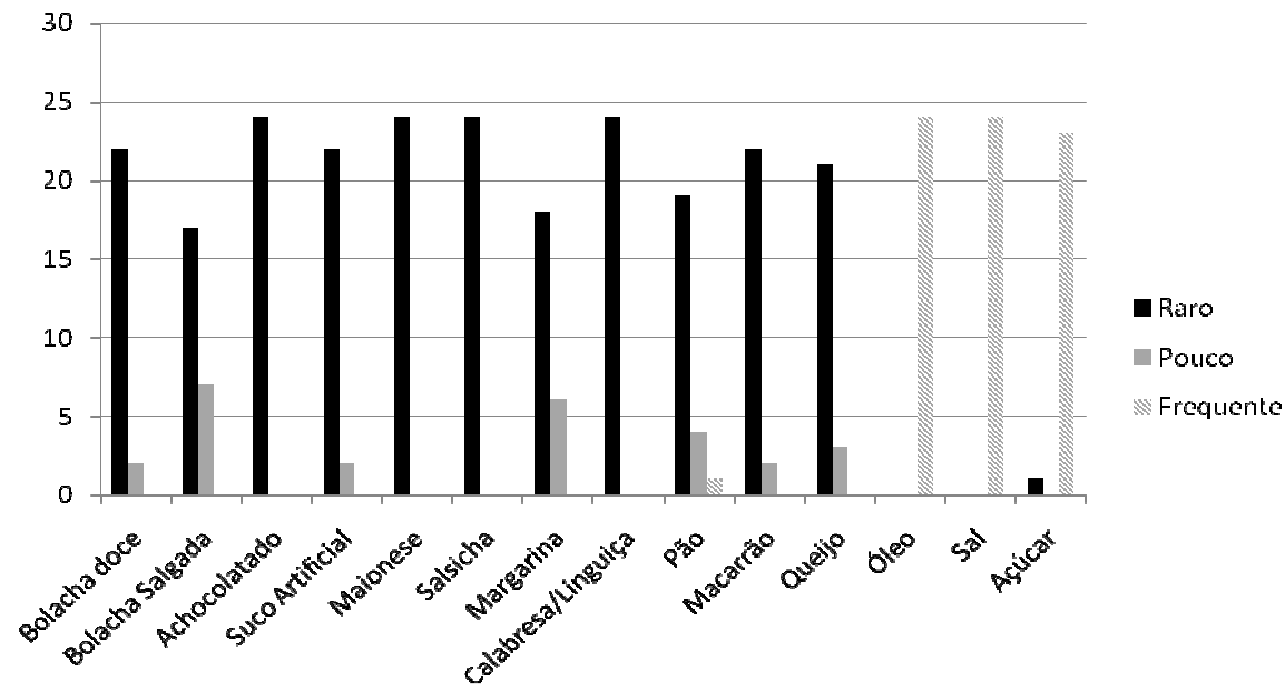

Fonte: elaboração própria. 


\section{Considerações finais}

Os resultados apresentados neste estudo reforçam a tese de que as práticas de produção agroalimentar na RDS não contradizem a premissa dessa UC e contribuem para a manutenção da segurança e a soberania alimentar. As práticas agrícolas vão ao encontro das três premissas da Segurança Alimentar, sendo elas: a disponibilidade de alimentos, considerada como a oferta em quantidade e qualidade obtida via produção para autoconsumo ou compra; o acesso, por meio da obtenção de alimentos quando esses não são produzidos - poder de compra, e; estabilidade de produção, a mão de obra e áreas disponíveis para cultivo possibilita suprir parte da demanda de alimentos do núcleo doméstico e desonera parte do orçamento para a compra de outros bens que não os alimentares.

Alguns agricultores demonstraram atender a um conjunto maior dessas características representativas no âmbito da segurança alimentar. Constatou-se que a produção agroalimentar pode não atender toda a demanda. No entanto, contribui para a manutenção de uma dieta alimentar diversificada, resultando na manutenção da segurança alimentar das unidades familiares.

O uso da terra para produção de alimentos de acordo com o apontado neste estudo faz-se presente na RDS, e nota-se que a produção agrícola é majoritariamente destinada à alimentação da família.

A venda de produtos agrícolas por meio do PAA também tem proporcionado ingresso de renda para os agricultores quilombolas, o que tem estimulado outros agricultores da RDS ao cultivo para venda, que não é exclusivo, uma vez que os produtos do cultivo também são consumidos na unidade familiar produtora.

Observa-se que a mudança da categoria de UC permitiu aos agricultores quilombolas passar a fazer uso da terra não mais na condição de clandestinidade e, ao mesmo tempo, possibilitou a manutenção de seus saberes agroambientais na produção de alimentos para autoconsumo e venda.

\section{REFERÊNCIAS}

BRANDÃO, C.R. Plantar, colher, comer: um estudo sobre o campesinato goiano. Rio de Janeiro: Graal, 2007. 181p.

BORN, R.H.; TALOCCHI, S. Conservação, desenvolvimento e serviços ambientais em área da Mata Atlântica: o caso do Vale do Ribeira (São Paulo). In: BORN, H. R.; TALOCCHI, S. (Orgs.). Proteção do capital social e ecológico por meio de compensação por serviços ambientais. São Paulo: Vitae Civilis, 2002. p.107-128.

CÂNDIDO, A. Os parceiros do Rio Bonito: um estudo sobre o caipira paulista e a transformação dos seus meios de vida. São Paulo: Duas Cidades, 2001. 376p.

CARRIL, L.F.B. Terras de Negros no Vale do Ribeira: Territorialidade e Resistência. 1995. 167f. Dissertação (Mestrado), Faculdade de Filosofia, Ciências e Letras, Universidade de São Paulo, São Paulo, 1995. 
CARNEIRO, M.J.; MALUF, R.S. (Orgs.). Para além da produção: multifuncionalidade e agricultura familiar. Rio de Janeiro: MAUAD, 2004. 230p.

CAMBUY, A.O.S. Perfil alimentar da comunidade quilombola João Surá: um estudo etnográfico. 2006. 67f. Monografia (Trabalho de Conclusão de Curso de Graduação), Faculdade de Nutrição, Universidade Federal do Paraná, Curitiba, 2006.

CGPAN. Relatório de gestão. Brasília, 2005. 51p. Disponível em: < http://189.28.128.100/nutricao/docs/geral/relatorio_2005_cgpan.pdf $>$. Acesso em: 12 jan. 2014.

DIEGUES, A.C. O mito moderno da natureza intocada. São Paulo: HUCITEC, 2000. 170p.

FERREIRA, S. R. B. Campesinidade e território quilombola no Norte do Espírito Santo. GEO grafia, Londrina, n. 16, p. 57-82, 2006.

FIGUEIREDO, M. C.; BOAZ, C. M. S.; BONACINA, C. M.; FABRICIO, F. K.; SILVA, K. V. C. L. Avaliação do padrão alimentar de quilombolas da comunidade do Limoeiro de Bacupari, Rio Grande do Sul, Brasil. Rev. Fac. Odontol., v.16, n.2, p.130-135, 2011.

GAZOLLA, M. Agricultura familiar, segurança alimentar e políticas públicas: uma análise a partir da produção para autoconsumo no território do Alto Uruguai. 2004. 284 p. Dissertação (Mestrado em Desenvolvimento Rural) - Faculdade de Ciências Econômicas, Universidade Federal do Rio Grande do Sul, Porto Alegre,2004.

GRISA, C.; GAZOLLA, M.; SCHNEIDER, S. A "produção invisível" na agricultura familiar: autoconsumo, segurança alimentar e políticas públicas de desenvolvimento rural. Agroalimentaria, vol.16, n.31, p.65-79, 2010.

HOLANDA, L.B.; BARROS FILHO, A.Z. Métodos aplicados em inquéritos alimentares. Rev. Paul. Pediat., v.24, n.1, p.62-70, 2006.

INSTITUTO DE TERRAS DO ESTADO DE SÃO PAULO. Relatório Técnico Científico sobre a comunidade de quilombo do Sapatu, no município de Eldorado, no Vale do Ribeira-SP. São Paulo, 2000.

INSTITUTO DE TERRAS DO ESTADO DE SÃO PAULO. Relatório Técnico Científico sobre a comunidade de quilombo de Ribeirão Grande e Terra Seca, no município de Barra do Turvo, no Vale do Ribeira-SP. São Paulo, 2006.

MALUF, R.S. Produtos agroalimentares, agricultura multifuncionalidade e desenvolvimento territorial no Brasil. In: MORREIRA, R.J.; COSTA, L.F.C. (Org.). Mundo rural e cultura. Rio de Janeiro: Mauad, 2009. p. 241-262. 
MINTZ, S.W. Comida e antropologia: uma breve revisão. Rev. Brasil. Ci. Soc., v.16, n.47, p.31-41, 2001.

NAVAS, R.; KANIKADAN, A.Y.S.; SANTOS, K.M.P; GARAVELLO, M.E.P.E. Transição alimentar em comunidade quilombola no litoral sul de São Paulo/Brasil. Rev. NERA, v.27, n.18, p.138-155, 2015.

PIPERATA, B. A. Nutritional status of Ribeirinhos in Brazil and the nutrition transition. Am. Journ. Physical Anthropol., v.133, n.2, p.868-878, 2007.

PLOEG, J. D. Camponeses e impérios alimentares: lutas por autonomia e sustentabilidade na era da globalização. Porto Alegre. Editora da UFRGS, Coleção Estudos Rurais. 2008.

PLOEG, J. D. O modo de produção camponês revisitado. In: S. Schneider (Org.). A diversidade da agricultura familiar. Porto Alegre: Editora da UFRGS, pp. 13-54, 2006.

REIJNTJES, C.; HAVEKORT, B.; WATERS-BAYER, A. Agricultura para o futuro:uma introdução à agricultura sustentável e de baixo uso de insumos externos. Rio de Janeiro: AS-PTA, 1994.324p.

SILVA, A. L.; BEGOSSI, A. Biodiversity, food consumption and ecological niche dimension: a study case of the Riverine populations from the Rio Negro, Amazonia, Brazil. Environ. Development and Sustainability, v. 11, n. 3, p. 1-24. 2007.

SANTILLI, J. Agrobiodiversidade e direitos dos agricultores. São Paulo: Ed. Petrópolis, 2009. 519p.

SANTOS, K.M.P; TATTO, N. A Agenda socioambiental de comunidades quilombolas do Vale do Ribeira. São Paulo: Instituto Socioambiental, 2008. 193p.

SILVA, T. P.; COSTABEBER, J. A. A (re)organização da produção: um estudo da segurança alimentar nos assentamentos de reforma agrária Santa Rita e Sepé Tiarajú, município de Capão do Cipó (RS). Revista NERA, v. 16, n. 23, p.131-149, 2013.

SÃO PAULO. Assembleia Legislativa, Lei no 12.810 de 21 de fevereiro de 2008. Altera os limites do Parque Estadual de Jacupiranga. Diário Oficial, São Paulo, 22 de fevereiro de 2008.

SOUZA, A. S.; SOARES, L. F. Análise das práticas alimentares das comunidades quilombolas do estado do Piauí. Rev. Nutrire, v.36, Supl., p.38-45, 2011.

STUCCHI, D. (coord.). Laudo Antropológico: Comunidades negras de Ivaporunduva, São Pedro, Pedro Cubas, Sapatu, Nhunguara, André Lopes, Maria Rosa e Pilões. São Paulo: Ministério Público Federal, 1998. 
VIERTLER, R.B. Ecologia cultural: uma antropologia da mudança. São Paulo: Ática, 1988. 61p.

Submetido em 08/04/2016

Aprovado em 08/07/2016

Katia Maria Pacheco dos Santos

Profa. Dra. da Faculdade de Agronomia e Medicina Veterinária - FAV da Universidade de Brasília (UNB).

E-mail: pachecokatia@unb.br

Maria Elisa de Paula Eduardo Garavello Profa. Dra. Escola Superior de Agricultura Luiz de Queiroz (ESALQ)/Universidade de São Paulo.

E-mail: mepegara@usp.br 